\title{
Space Vector PWM-DTC Strategy for Single-Phase Induction Motor Control
}

\author{
Ademir Nied ${ }^{1}$, José de Oliveira ${ }^{1}$, Rafael de Farias Campos ${ }^{1}$, \\ Seleme Isaac Seleme Jr. ${ }^{2}$ and Luiz Carlos de Souza Marques ${ }^{3}$ \\ ${ }^{1}$ State University of Santa Catarina \\ ${ }^{2}$ Federal University of Minas Gerais \\ ${ }^{3}$ Federal University of Santa Maria \\ Brazil
}

\section{Introduction}

Single-phase induction motors are widely used in fractional and sub-fractional horsepower applications, mostly in domestic and commercial applications such as fans, refrigerators, air conditioners, etc., operating at constant speed or controlled by an on/off strategy which can result in poor efficiency and low-power factor. In terms of construction, these types of motors usually have a main and an auxiliary stator winding, are asymmetrical and are placed 90 degrees apart from each other. The rotor is usually the squirrel-cage type. The asymmetry presented in the stator windings is due to the fact that these windings are designed to be electrically different so the difference between the stator windings currents can produce a starting torque (Krause et al., 1995). Since it has main and auxiliary stator windings, the singlephase induction motor is also known as a two-phase asymmetric induction motor.

In recent years, with the growing concern about low-cost operation and the efficient use of energy, the advance in motor drive control technology made it possible to apply these motors to residential applications with more efficiency. Different inverter topologies have been proposed to drive single-phase induction motors, providing ways to save energy. In dos Santos et al. (2010) different ac drive systems are conceived for multiple single-phase motor drives with a single dc-link voltage to guarantee installation cost reduction and some individual motor controls. In Wekhande et al. (1999) and Jabbar et al. (2004), Campos et al. (2007a) and Campos et al. (2007b), two topologies are considered. One is a Half-bridge inverter and the other is a three-leg inverter. The cost difference between the two topologies lays in the fact that the H-bridge inverter needs two large capacitors in the dc link rated for dc link voltage. Also, there is a need of two large resistors connected in parallel with the capacitors to balance the voltage of the capacitors.

Despite the fact that the three-leg inverter has more switches, the development of power modules and the need for just one capacitor in the dc link have decreased the topology cost. Along with the reduced cost, a more efficient use of the dc link voltage is achieved.

Besides the effort for developing more efficient driving topologies, many strategies to control single-phase motors have been proposed. In Jacobina et al. (1999), rotor-flux control, stator-flux control and direct torque control (DTC) (Takahashi and Noguchi, 1986) are analyzed. The main drawback of the two first strategies is that they use an encoder to obtain 
the speed signal. Since there is no need for speed and position signals, a DTC scheme appears to be a suitable solution. But it has some disadvantages such as current and torque distortions, variable switching frequency and low-speed operation problems (Buja and Kazmierkowski, 2004). In Neves et al. (2002), a DTC strategy is applied for a single-phase motor and the performance is improved with the use of pulse width modulation.

Along with control strategies and driver topologies, many researchers have investigated ways to optimize modulation techniques applied in single-phase induction motor drives. In Jabbar et al. (2004), space-vector modulation (SVPWM) is used to reduce the torque ripple and alleviate the harmonic content at the terminals of the single-phase induction motor being driving by a three-leg inverter. In Chaumit and Kinnares (2009) the proposed SVPWM method controls the two-phase voltage outputs of an unbalanced two-phase induction motor drive by varying the modulation index and voltage factors.

In this chapter, the authors are interested in studying the DTC strategy combined with the SVPWM applied to a three-leg inverter topology to drive a single-phase induction motor.

\section{Single-phase induction motor model}

A single-phase induction motor with main and auxiliary windings is designed to be electrically different. In order to make the motor self-starting, a capacitor is connected in series with the auxiliary winding.

When the windings of a single-phase induction motor are fed independently (i.e., using a voltage source inverter) one can consider a single-phase induction motor an example of an unsymmetrical two-phase induction motor.

In this section, the mathematical model of a single-phase induction motor will be derived. As is commonly done, the derivation of the motor model is based on classical assumptions:

- The stator and rotor windings are in space quadrature;

- The rotor windings are symmetrical;

- The magnetic circuit is linear and the air-gap length is constant;

- A sinusoidal magnetic field distribution produced by the motor windings appears in the air gap;

- $\quad$ The motor is a squirrel-cage type. Therefore the rotor voltages are zero.

Since the single-phase induction motor will be considered as acting as a two-phase system, to derive the dynamic motor model of the two-phase system, a common reference frame ( $a$ b) will be used, as shown in Fig. 1 .

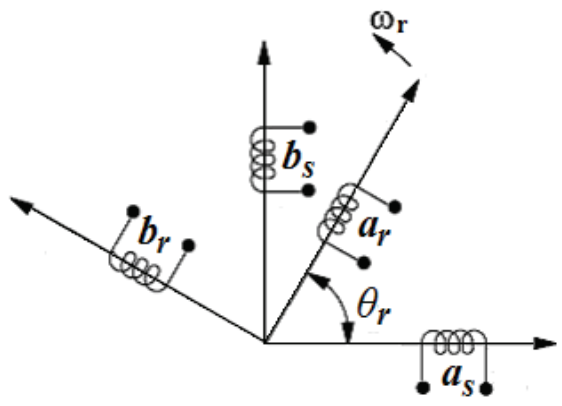

Fig. 1. Common reference frame $(a-b)$. 
Since the stator windings are in space quadrature, there is no magnetic coupling between them. The same consideration is applied to the rotor windings. According to Krause et al. (1995), the relations between the fluxes and currents can be established as:

$$
\left[\begin{array}{c}
\lambda_{a s} \\
\lambda_{b s} \\
\lambda_{a r} \\
\lambda_{b r}
\end{array}\right]=\left[\begin{array}{llll}
L_{a s a s} & L_{a s b s} & L_{a s a r} & L_{a s b r} \\
L_{b s a s} & L_{b s b s} & L_{b s a r} & L_{b s b r} \\
L_{a r a s} & L_{a r b s} & L_{a r a r} & L_{a r b r} \\
L_{b r a s} & L_{b r b s} & L_{b r a r} & L_{b r b r}
\end{array}\right]\left[\begin{array}{c}
i_{a s} \\
i_{b s} \\
i_{a r} \\
i_{b r}
\end{array}\right]
$$

In Equation (1), $L_{a s a s(b s b s)}$ is the stator windings self-inductance; $L_{a r a r(b r b r)}$ is the rotor windings self-inductance; $L_{a s b r(b r a s),} L_{a r b s(b s a r)}$ and $L_{a s a r(a r a s)}, L_{b s b r(b r b s)}$ are the mutual inductance between the stator and rotor windings. Since the stator windings are in space quadrature and asymmetric, and the rotor windings are in space quadrature and symmetric, the following relations can be written:

$$
\begin{gathered}
L_{a s a s}=L_{a s} \\
L_{b s b s}=L_{b s} \\
L_{a s b s}=L_{b s a s}=0 \\
L_{a r b r}=L_{b r a r}=0 \\
L_{a r a r}=L_{b r b r}=L_{r}
\end{gathered}
$$

The self-inductances of stator and rotor are composed of a leakage inductance and a magnetizing inductance. That way, a new set of equations can be derived:

$$
\begin{gathered}
L_{a s}=L_{l a s}+L_{m a s} \\
L_{b s}=L_{l b s}+L_{m b s} \\
L_{r}=L_{l r}+L_{m r}
\end{gathered}
$$

where $\left(L_{l a s}, L_{l b s}\right)$ and $\left(L_{m a s}, L_{m b s}\right)$ indicate the stator leakage inductance and magnetizing inductance, respectively, and $L_{l r}$ and $L_{m r}$ indicate the rotor leakage inductance and magnetizing inductance, respectively. Since the rotor windings are assumed to be symmetric, Equation (9) expresses the rotor windings.

As shown in Fig. 1, there is an angular displacement between the stator and rotor windings establishing a magnetic coupling between them which results in a mutual inductance. The equation for the mutual inductances may be expressed in matrix form

$$
L_{s r}=\left[\begin{array}{cc}
L_{s r a} \cos \theta_{r} & -L_{s r a} \sin \theta_{r} \\
L_{s r b} \sin \theta_{r} & L_{s r b} \cos \theta_{r}
\end{array}\right]
$$

where $L_{s r a}$ and $L_{s r b}$ are the amplitude of the mutual inductances.

Thus, the Equation (1) can be rewritten as 


$$
\left[\begin{array}{l}
\lambda_{a s} \\
\lambda_{b s} \\
\lambda_{a r} \\
\lambda_{b r}
\end{array}\right]=\left[\begin{array}{cccc}
L_{a s} & 0 & L_{s r a} \cos \theta_{r} & -L_{s r a} \sin \theta_{r} \\
0 & L_{b s} & L_{s r b} \sin \theta_{r} & L_{s r b} \cos \theta_{r} \\
L_{s r a} \cos \theta_{r} & L_{s r b} \sin \theta_{r} & L_{r} & 0 \\
-L_{s r a} \sin \theta_{r} & L_{s r b} \cos \theta_{r} & 0 & L_{r}
\end{array}\right]\left[\begin{array}{l}
i_{a s} \\
i_{b s} \\
i_{a r} \\
i_{b r}
\end{array}\right]
$$

The voltage equations expressed in the common reference frame may be written as

$$
\begin{gathered}
{\left[\begin{array}{c}
v_{a s} \\
v_{b s}
\end{array}\right]=\left[\begin{array}{cc}
r_{a s} & 0 \\
0 & r_{b s}
\end{array}\right]\left[\begin{array}{l}
i_{a s} \\
i_{b s}
\end{array}\right]+\frac{d}{d t}\left[\begin{array}{l}
\lambda_{a s} \\
\lambda_{b s}
\end{array}\right]} \\
{\left[\begin{array}{l}
0 \\
0
\end{array}\right]=\left[\begin{array}{cc}
r_{r} & 0 \\
0 & r_{r}
\end{array}\right]\left[\begin{array}{l}
i_{a r} \\
i_{b r}
\end{array}\right]+\frac{d}{d t}\left[\begin{array}{l}
\lambda_{a r} \\
\lambda_{b r}
\end{array}\right]}
\end{gathered}
$$

Inserting Equation (11) in Equations (12) and (13), the single-phase induction motor model acting as a two-phase system can be mathematically expressed by

$$
\left[\begin{array}{c}
v_{a s} \\
v_{b s} \\
0 \\
0
\end{array}\right]=\left[\begin{array}{cccc}
r_{a s}+\frac{d}{d t} L_{a s} & 0 & \frac{d}{d t} L_{s r a} \cos \theta_{r} & -\frac{d}{d t} L_{s r a} \sin \theta_{r} \\
0 & r_{b s}+\frac{d}{d t} L_{b s} & \frac{d}{d t} L_{s r b} \sin \theta_{r} & \frac{d}{d t} L_{s r b} \cos \theta_{r} \\
\frac{d}{d t} L_{s r a} \cos \theta_{r} & \frac{d}{d t} L_{s r b} \sin \theta_{r} & r_{r}+\frac{d}{d t} L_{r} & 0 \\
-\frac{d}{d t} L_{s r a} \sin \theta_{r} & \frac{d}{d t} L_{s r b} \cos \theta_{r} & 0 & r_{r}+\frac{d}{d t} L_{r}
\end{array}\right]\left[\begin{array}{c}
i_{a s} \\
i_{b s} \\
i_{a r} \\
i_{b r}
\end{array}\right]
$$

The torque can be determined as

$$
T_{e}=\left[\begin{array}{c}
i_{a r} \\
i_{b r}
\end{array}\right]^{T} \frac{d\left(L_{s r}\right)^{T}}{d \theta_{r_{-} m e c h}}\left[\begin{array}{c}
i_{a s} \\
i_{b s}
\end{array}\right]
$$

Since $\theta_{r}=p \theta_{r_{-} \text {mech }}$, where $p$ is the number of pole pairs and $\theta_{r}$ is the electrical angle, and $\theta_{r_{-} m e c h}$ is the actual angular displacement of the rotor, the Equation (15) can be rewritten

$$
T_{e}=p \cdot\left[\begin{array}{l}
i_{a r} \\
i_{b r}
\end{array}\right]^{T} \frac{d\left(L_{s r}\right)^{T}}{d \theta_{r}}\left[\begin{array}{l}
i_{a s} \\
i_{b s}
\end{array}\right]
$$

In expanded form, (16) becomes

$$
T_{e}=p\left[-i_{a s} L_{s r a}\left(i_{a r} \sin \theta_{r}+i_{b r} \cos \theta_{r}\right)+i_{b s} L_{s r b}\left(i_{a r} \cos \theta_{r}-i_{b r} \sin \theta_{r}\right)\right]
$$

According to Krause et al. (1995), in order to obtain the motor mathematical model with constant parameters, it is necessary to transform all the variables to the stationary reference frame $(d-q)$ as shown in Fig. 2. That way $\theta_{r}=0$.

A transformation matrix is necessary in order to establish the new reference frame. Thus

$$
T=\left[\begin{array}{cc}
\cos \theta_{r} & \sin \theta_{r} \\
-\sin \theta_{r} & \cos \theta_{r}
\end{array}\right] ; T^{-1}=\left[\begin{array}{cc}
\cos \theta_{r} & -\sin \theta_{r} \\
\sin \theta_{r} & \cos \theta_{r}
\end{array}\right]
$$




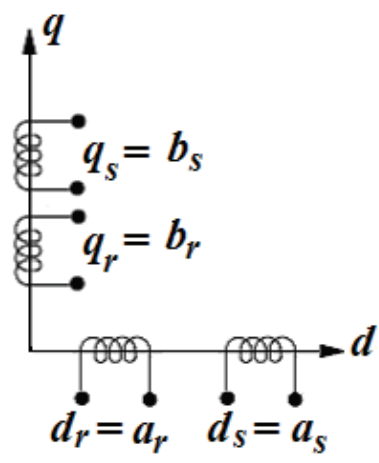

Fig. 2. Stationary reference frame $(d-q)$.

Applying the transformation matrix to Equations (14) and (17), then

$$
\left[\begin{array}{l}
v_{d s}^{s} \\
v_{q s}^{s} \\
0 \\
0
\end{array}\right]=\left[\begin{array}{cccc}
r_{d s}+\frac{d L_{d s}}{d t} & 0 & \frac{d L_{s r d}}{d t} & 0 \\
0 & r_{q s}+\frac{d L_{q s}}{d t} & 0 & \frac{d L_{s r q}}{d t} \\
\frac{d L_{s r d}}{d t} & p \omega_{r} L_{s r q} & r_{r}+\frac{d L_{r}}{d t} & p \omega_{r} L_{r} \\
-p \omega_{r} L_{s r d} & \frac{d L_{s r q}}{d t} & -p \omega_{r} L_{r} & r_{r}+\frac{d L_{r}}{d t}
\end{array}\right]\left[\begin{array}{l}
i_{d s}^{s} \\
i_{q s}^{s} \\
i_{d r}^{s} \\
i_{q r}^{s}
\end{array}\right]
$$

where the superscript $s$ denotes the stationary frame. The torque can also be expressed as

$$
p\left(T_{e}-T_{m}\right)=J \frac{d \omega_{r}}{d t}+B \omega_{r}
$$

This analytical approach represents the single-phase induction motor as an asymmetric twophase motor. The $d q$ voltages, currents, and fluxes for stator and rotor are, respectively: $v_{d s}^{s}, v_{q s}^{s}, i_{d s}^{s}, i_{q s}^{s}, i_{d r}^{s}, i_{q r}^{s}, \lambda_{d s}^{s}, \lambda_{q s}^{s}, \lambda_{d r}^{s}, \lambda_{q r}^{s}$. The terms $L_{d s}, L_{q s}, L_{r}, L_{s r d}, L_{s r q}$ denote the stator and rotor self-inductance and their respective mutual inductance. The stator and rotor resistance are denoted by $r_{d s}, r_{q s}, r_{r}$. The motor electromagnetic-torque and the load torque are indicated by $T_{e}$ and $T_{m}$, respectively. The moment of inertia, viscous friction coefficient and the motor speed are, respectively: $J, B$ and $\omega_{r}$.

One of the drawbacks of dealing with an asymmetric motor lies in the pulsating electromagnetic torque that occurs due to the unbalance between the stator variables, as can be seen in (19) and (20). To overcome this drawback and to create a symmetric model, a transformation of the stator variables employing the mutual inductances was proposed by Correa et al. (2004). The transformation matrix and its application can be written as 


$$
\begin{gathered}
S=\left[\begin{array}{ll}
1 & 0 \\
0 & n
\end{array}\right] \\
{\left[\begin{array}{c}
v_{d s}^{s} \\
v_{q s}^{s}
\end{array}\right]=S\left[\begin{array}{l}
v_{d s 1}^{s} \\
v_{q s 1}^{s}
\end{array}\right]} \\
{\left[\begin{array}{l}
i_{d s}^{s} \\
i_{q s}^{s}
\end{array}\right]=S^{-1}\left[\begin{array}{l}
i_{d s 1}^{s} \\
i_{q s 1}^{s}
\end{array}\right]} \\
{\left[\begin{array}{l}
\lambda_{d s}^{s} \\
\lambda_{q s}^{s}
\end{array}\right]=S^{-1}\left[\begin{array}{l}
\lambda_{d s 1}^{s} \\
\lambda_{q s 1}^{s}
\end{array}\right]}
\end{gathered}
$$

The transformation element can be written as $n=\frac{L_{s r d}}{L_{s r q}}$.

When these transformations are applied to the mathematical model of the motor, the unbalance between the main and auxiliary windings stator variables is eliminated. The new symmetrical model of the single-phase induction motor acting as a two-phase system can be given by the following equations:

$$
\begin{gathered}
{\left[\begin{array}{c}
v_{d s 1}^{s} \\
v_{q s 1}^{s}
\end{array}\right]=\left[\begin{array}{cc}
r_{d s} & 0 \\
0 & r_{q s}^{\prime}
\end{array}\right] \cdot\left[\begin{array}{l}
i_{d s 1}^{s} \\
i_{q s 1}^{s}
\end{array}\right]+\frac{d}{d t}\left[\begin{array}{c}
\lambda_{d s 1}^{s} \\
\lambda_{q s 1}^{s}
\end{array}\right]} \\
{\left[\begin{array}{c}
v_{d r}^{s} \\
v_{q r}^{s}
\end{array}\right]=\left[\begin{array}{cc}
r_{r} & 0 \\
0 & r_{r}
\end{array}\right] \cdot\left[\begin{array}{l}
i_{d r}^{s} \\
i_{q r}^{s}
\end{array}\right]+\frac{d}{d t}\left[\begin{array}{c}
\lambda_{d r}^{s} \\
\lambda_{q r}^{s}
\end{array}\right]+\omega_{r}\left[\begin{array}{cc}
0 & 1 \\
-1 & 0
\end{array}\right] \cdot\left[\begin{array}{c}
\lambda_{d r}^{s} \\
\lambda_{q r}^{s}
\end{array}\right]} \\
{\left[\begin{array}{c}
\lambda_{d s 1}^{s} \\
\lambda_{q s 1}^{s}
\end{array}\right]=\left[\begin{array}{cc}
L_{d s} & 0 \\
0 & L_{q s}^{\prime}
\end{array}\right] \cdot\left[\begin{array}{l}
i_{d s 1}^{s} \\
i_{q s 1}^{s}
\end{array}\right]+\left[\begin{array}{cc}
L_{s r d} & 0 \\
0 & L_{s r d}
\end{array}\right] \cdot\left[\begin{array}{l}
i_{d r}^{s} \\
i_{q r}^{s}
\end{array}\right]} \\
{\left[\begin{array}{c}
\lambda_{d r}^{s} \\
\lambda_{q r}^{s}
\end{array}\right]=\left[\begin{array}{cc}
L_{r} & 0 \\
0 & L_{r}
\end{array}\right] \cdot\left[\begin{array}{l}
i_{d r}^{s} \\
i_{q r}^{s}
\end{array}\right]+\left[\begin{array}{cc}
L_{s r d} & 0 \\
0 & L_{s r d}
\end{array}\right] \cdot\left[\begin{array}{l}
i_{d s 1}^{s} \\
i_{q s 1}^{s}
\end{array}\right]} \\
T_{e}=P L_{s r d}\left(i_{q s 1}^{s} i_{d r}^{s}-i_{d s 1}^{s} i_{q r}^{s}\right)
\end{gathered}
$$

where $L_{q s}^{\prime}=n^{2} L_{q s}$ and $r_{q s}^{\prime}=n^{2} r_{q s}$.

According to Correa et al. (2004), if the asymmetry that appears in the motor model depends only on the number of turns of each stator winding, then the ratio presented by $n$ will corresponds approximately to refer the auxiliary winding variables to the main winding. Also, if the inductances are slightly different, then $L_{q s}^{\prime} \approx L_{d s}$. 
Observing Equation (26) there is an asymmetry between the stator resistances. This term can be isolated

$$
\left[\begin{array}{l}
v_{d s 1}^{s} \\
v_{q s 1}^{s}
\end{array}\right]=\left[\begin{array}{cc}
r_{d s} & 0 \\
0 & r_{d s}
\end{array}\right] \cdot\left[\begin{array}{l}
i_{d s 1}^{s} \\
i_{q s 1}^{s}
\end{array}\right]+\frac{d}{d t}\left[\begin{array}{l}
\lambda_{d s 1}^{s} \\
\lambda_{q s 1}^{s}
\end{array}\right]+\Delta r
$$

The term $\Delta r$ is given by

$$
\Delta r=\left[\begin{array}{c}
0 \\
\left(n^{2} r_{q s}-r_{d s}\right) i_{q s 1}^{s}
\end{array}\right]
$$

When dealing with motor control, it is necessary to write the dynamic equations of the induction motor in an arbitrary reference frame. This transformation allows the $d-q$ variables to be treated as dc signals, which is commonly used in control theory.

If $\Delta r$ is considered negligible, a symmetric model of the single-phase induction motor in the arbitrary reference frame can be derived as shown in Fig. 3.

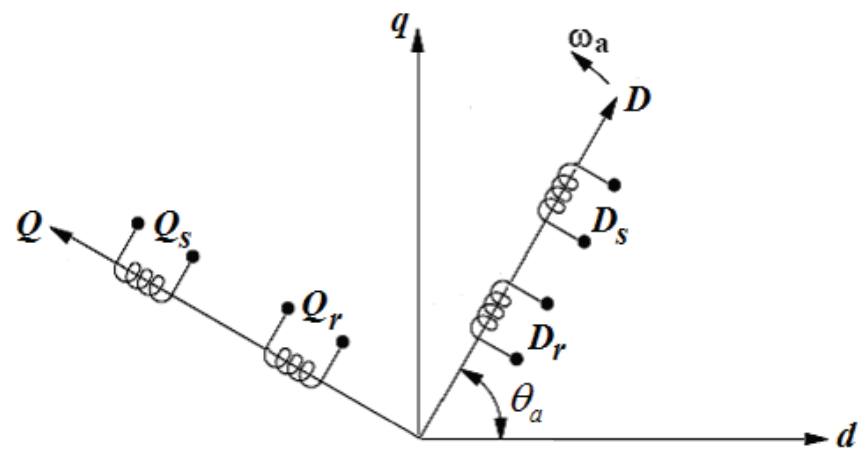

Fig. 3. Revolving reference frame.

The transformation matrix is given by

$$
T_{a}=\left[\begin{array}{cc}
\cos \theta_{a} & -\sin \theta_{a} \\
\sin \theta_{a} & \cos \theta_{a}
\end{array}\right] ; T_{a}^{-1}=\left[\begin{array}{cc}
\cos \theta_{a} & \sin \theta_{a} \\
-\sin \theta_{a} & \cos \theta_{a}
\end{array}\right]
$$

When applying the transformation to the motor model based on the stationary reference frame, given by (26) and (27), the resulting equations can be written in a different matrix form:

$$
\begin{aligned}
& {\left[\begin{array}{l}
v_{D s 1}^{a} \\
v_{\mathrm{Q} s 1}^{a}
\end{array}\right]=\left[\begin{array}{ll}
r_{s} & 0 \\
0 & r_{s}
\end{array}\right] \cdot\left[\begin{array}{l}
i_{D s 1}^{a} \\
i_{\mathrm{Q} s 1}^{a}
\end{array}\right]+\frac{d}{d t}\left[\begin{array}{l}
\lambda_{\mathrm{Ds} 1}^{a} \\
\lambda_{\mathrm{Q} s 1}^{a}
\end{array}\right]+\omega_{a}\left[\begin{array}{cc}
0 & -1 \\
1 & 0
\end{array}\right] \cdot\left[\begin{array}{c}
\lambda_{\mathrm{D} s 1}^{a} \\
\lambda_{\mathrm{Q} s 1}^{a}
\end{array}\right]} \\
& {\left[\begin{array}{l}
0 \\
0
\end{array}\right]=\left[\begin{array}{cc}
r_{r} & 0 \\
0 & r_{r}
\end{array}\right] \cdot\left[\begin{array}{l}
i_{D r}^{a} \\
i_{\mathrm{Q} r}^{a}
\end{array}\right]+\frac{d}{d t}\left[\begin{array}{c}
\lambda_{\mathrm{D} r}^{a} \\
\lambda_{\mathrm{Q} r}^{a}
\end{array}\right]+\left(\omega_{a}-p \omega_{r}\right)\left[\begin{array}{cc}
0 & -1 \\
1 & 0
\end{array}\right] \cdot\left[\begin{array}{l}
\lambda_{\mathrm{D} r}^{a} \\
\lambda_{\mathrm{Q} r}^{a}
\end{array}\right]}
\end{aligned}
$$




$$
\begin{aligned}
& {\left[\begin{array}{l}
\lambda_{D s 1}^{a} \\
\lambda_{\mathrm{Q} s 1}^{a}
\end{array}\right]=\left[\begin{array}{cc}
L_{d s} & 0 \\
0 & L_{d s}
\end{array}\right] \cdot\left[\begin{array}{l}
i_{D s 1}^{a} \\
i_{\mathrm{Q} s}^{a}
\end{array}\right]+\left[\begin{array}{cc}
L_{s r d} & 0 \\
0 & L_{s r d}
\end{array}\right] \cdot\left[\begin{array}{c}
i_{D r}^{a} \\
i_{Q r}^{a}
\end{array}\right]} \\
& {\left[\begin{array}{c}
\lambda_{\mathrm{D} r}^{a} \\
\lambda_{\mathrm{Q} r}^{a}
\end{array}\right]=\left[\begin{array}{cc}
L_{r} & 0 \\
0 & L_{r}
\end{array}\right] \cdot\left[\begin{array}{l}
i_{D r}^{a} \\
i_{Q r}^{a}
\end{array}\right]+\left[\begin{array}{cc}
L_{s r d} & 0 \\
0 & L_{s r d}
\end{array}\right] \cdot\left[\begin{array}{l}
i_{D s 1}^{a} \\
i_{\mathrm{Q} 1}^{a}
\end{array}\right]}
\end{aligned}
$$

The torque equation yields

$$
T_{e}=p L_{s r d}\left[i_{Q s 1}^{a} i_{D r}^{a}-i_{D s 1}^{a} i_{Q r}^{a}\right]
$$

\section{Conventional DTC scheme for single-phase induction motor}

The basic DTC scheme consists of a logical switching table, which calculates the right voltage vector to be applied by the inverter to obtain as fast a torque response as possible at every instant. The control is based on error between the references and estimated values of torque and flux magnitude and also uses the position of the estimated flux vector. The torque and flux magnitude error signals are the inputs to the torque and flux hysteresis controllers, respectively. That way, both the stator flux magnitude and the developed torque can be directly controlled by proper selection of stator voltage space vectors in order to reduce the torque and flux errors within the prefixed limits. The hysteresis determines the inverter switching frequency, which varies with the synchronous speed and load conditions. This technique achieves robust and fast torque response. Fig 4 shows the block diagram for the conventional DTC scheme applied to a single-phase induction motor.

To determine the proper voltage vectors to be applied, a logical switching table must be made. This can be achieved by dividing the $d q$ plane into six sectors. A power inverter will be employed in a three-leg configuration. That way the $d q$ plane has the form of an asymmetric hexagon, as shown in Fig 5. There are six active vectors and two zero vectors ( $V_{7}$ and $V o$ ). The zero vectors are used to reduce the torque. Since a single-phase induction motor can be viewed as a two-phase induction motor, there is no need for three-to-two phase transformation for the primary voltage and current. Another aspect concerning this method of control is the absence of field orientation which makes the control task a less complex issue.

So for the conventional DTC, the following equations are derived from (26) to estimate the stator flux

$$
\begin{aligned}
& \lambda_{s d}^{s}=\int\left(v_{s d}^{s}-r_{s d} i_{s d}^{s}\right) d t \\
& \lambda_{s q}^{s}=\int\left(v_{s q}^{s}-r_{s q} i_{s q}^{s}\right) d t
\end{aligned}
$$

The electromagnetic torque as a function of stator variables can be written as:

$$
T_{e}=p\left(i_{s q}^{s} \lambda_{s d}^{s}-i_{s d}^{s} \lambda_{s q}^{s}\right)
$$

Estimation of the stator flux by pure integration can present instability, especially at low speeds. This problem can be overcome by using a low-pass filter instead of a pure integrator or other filtering techniques presented in $\mathrm{Hu}$ (1998). 


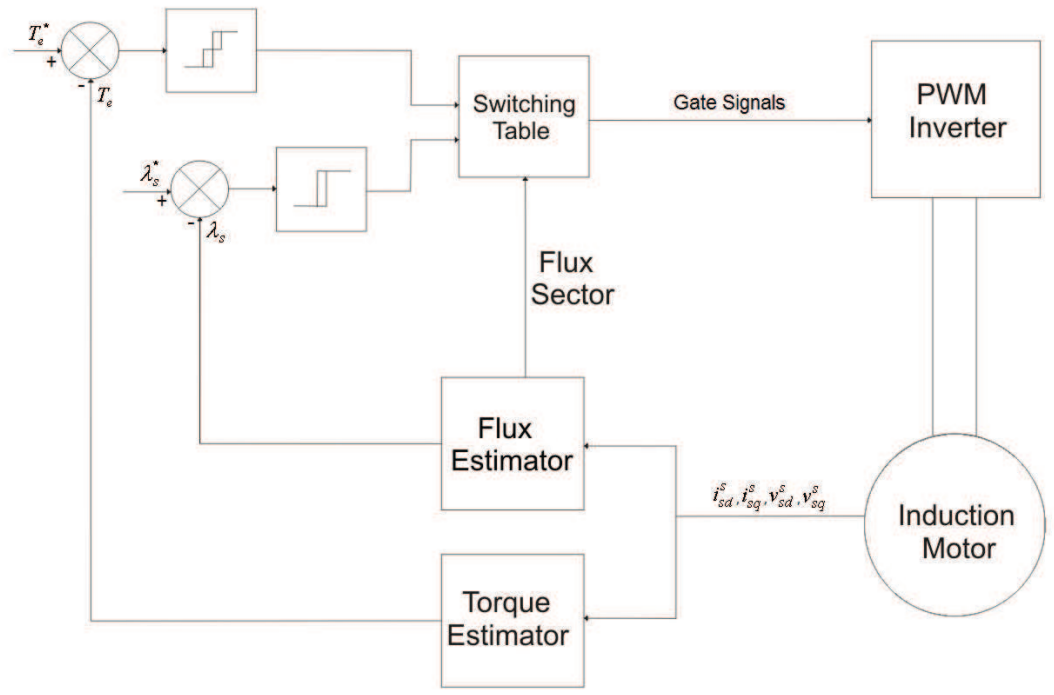

Fig. 4. Block diagram of the basic DTC scheme.

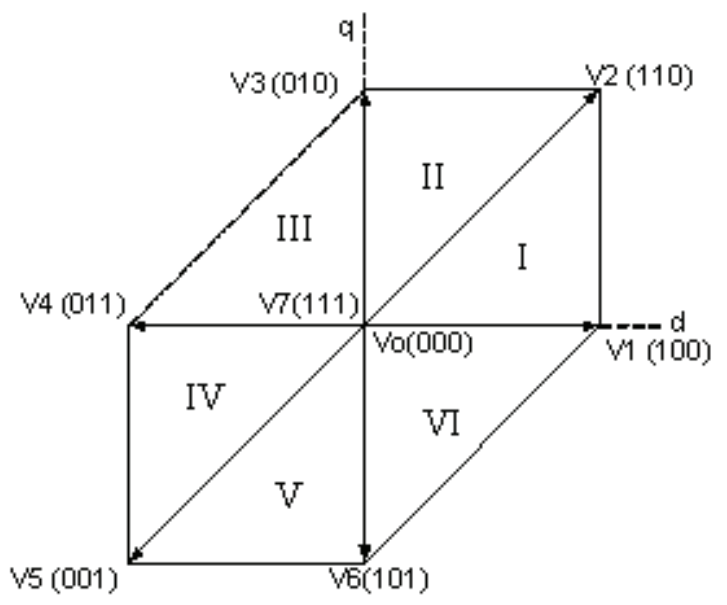

Fig. 5. Space-vectors hexagon.

Since DTC uses hysteresis control resulting in a so-called bang-bang control of the torque and flux, the result is a fast response of the control commands. However, the steady state performance is characterized by undesirable ripples in current, flux and torque. To avoid such effects, a high switching frequency should be delivered by the hysteresis loops. But the amplitude of the hysteresis band has a strong effect on those undesirable ripples mentioned above (Noguchi and Takahashi, 1997). To eliminate these issues, instead of using a switching table, a pulse width modulator can be used. Basically, the DTC scheme can be implemented by means of a closed-loop PI controller which will calculate the required stator 
voltage vector and then will be synthesized by a PWM technique (Jabbar et al., 2004). Therefore, the pulse width modulator is used to optimize the steady state drive performance.

\section{Space vector modulation technique}

To control the three-leg inverter driving a single-phase induction motor indirectly, space vector PWM can be employed. This approach is known to deliver less harmonic distortion in the output voltages applied to the phases of the induction motor. Consequently, the ripples in the stator current are diminished and a smooth flux and torque waveform is obtained.

In Correa et al. (2002), Tomaselli et al. (2004) and Jabbar et al. (2004), a space vector modulation applied to a three-leg inverter driving a single-phase motor is presented. As shown in Fig. 6, the spatial disposition of the space vectors differs from the one found when the same inverter system drives a three-phase induction motor. In the latter, the space vector displays a symmetric hexagon (Zhou, 2002). For the single-phase system, the space vectors form an asymmetric hexagon (Jabbar et al., 2004). Since the voltages supplied by the threeleg inverter to the motor phases are sinusoidal waves $90^{\circ}$ degrees apart from each other, the stator voltage vector can be decomposed into real and imaginary parts,

$$
v^{*}=v_{d s}^{s^{*}}+j v_{q s}^{s^{*}}
$$

The reference vector $v^{*}$ is used to determine the switching signals that will drive the threeleg inverter. The adjacent vectors $v_{d s}^{s^{*}}$ and $v_{q s}^{s^{*}}$ display the magnitude of the resulting switching vectors. Similar to the three-phase inverter feeding a three-phase induction motor, in a three-phase inverter feeding a two-phase induction motor there are eight voltage vectors to be applied (six active vectors and two zero vectors). Table I presents the eight voltage vectors that can be applied to the motor $\left(V_{n}\right.$ indicates the resulting space vectors with $n=0,1,2, \ldots, 7)$.

From the asymmetric hexagon, one can see that there are four vectors with amplitude $\mathrm{E}$ $\left(V_{1}, V_{3}, V_{4}, V_{6}\right)$, two vectors with amplitude $\sqrt{2} \mathrm{E}\left(V_{2}, V_{5}\right)$ and two null vectors $\left(V_{0}, V_{7}\right)$.

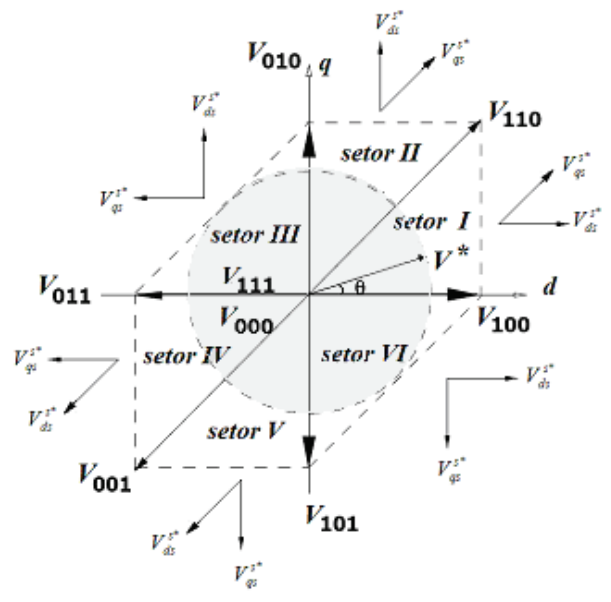

Fig. 6. Space Vectors spatial disposition. 


\begin{tabular}{|c||c|c|c|c|c|}
\hline$V_{n}$ & $\mathrm{~S}_{1}$ & $\mathrm{~S}_{2}$ & $\mathrm{~S}_{3}$ & $v_{d s}^{s}$ & $v_{q s}^{s}$ \\
\hline \hline$V_{0}$ & 0 & 0 & 0 & 0 & 0 \\
\hline$V_{1}$ & 1 & 0 & 0 & $\mathrm{E}$ & 0 \\
\hline$V_{2}$ & 1 & 1 & 0 & $\mathrm{E}$ & $\mathrm{E}$ \\
\hline$V_{3}$ & 0 & 1 & 0 & 0 & $\mathrm{E}$ \\
\hline$V_{4}$ & 0 & 1 & 1 & $-\mathrm{E}$ & 0 \\
\hline$V_{5}$ & 0 & 0 & 1 & $-\mathrm{E}$ & $-\mathrm{E}$ \\
\hline$V_{6}$ & 1 & 0 & 1 & 0 & $-\mathrm{E}$ \\
\hline$V_{7}$ & 1 & 1 & 1 & 0 & 0 \\
\hline
\end{tabular}

Table 1. Switching states and the adjacent vectors amplitude.

According to Jabbar et al. (2004), the reference vector and the adjacent vectors can be related by the following equation:

$$
T_{p w m} V^{*}=t_{d s} \cdot V_{d s}^{s^{*}}+t_{q s} \cdot V_{q s}^{s^{*}}
$$

In Equation (19), $t_{d s}$ and $t_{q s}$ are the durations in time in which the vectors $V_{d s}^{s^{*}}$ and $V_{q s}^{s^{*}}$ are within period $T_{p w m}$. The period of duration of the zero vectors can be defined by

$$
t_{0}=T_{p w m}-t_{d s}-t_{q s}
$$

\section{SVPWM-DTC Proposed Scheme}

As mentioned in Section 3, to optimize the steady state performance and to diminish the switching harmonics, a pulse width modulator can be applied. An improvement can be achieved when torque and stator flux magnitude are controlled by PI controllers using a closed-loop. The DTC strategy adapted to single-phase induction motors was discussed in Jacobina et al. (1999) and Neves et al. (2002). Fig. 7 shows the proposed scheme. The essence of DTC is kept, since its principle of accelerating the flux vector to increase torque is maintained, and there is no need for speed or position signals. The output signals of the PI controllers can be viewed as stator voltage components operating in Cartesian coordinates. After the reference frame transformation, the PWM is fed with the stator voltage components in the stationary frame. The control strategy relies on the stator flux orientation; therefore, the arbitrary reference frame should be aligned with the stator flux vector, $\theta_{a}=\theta_{s f}$.

The condition to achieve the field orientation can be expressed by

$$
\lambda_{D s 1}^{s f}=\lambda_{s} ; \lambda_{\mathrm{Q} s 1}^{s f}=0
$$

To determine the dynamic equations for the proposed technique, some algebraic manipulations must be done. Taking the Equations (34), (35), (37), aligned with the stator reference frame, the designed control signals can be derived:

$$
v_{D s 1}^{s f}=\frac{\lambda_{s}}{\tau_{d s} \sigma_{s}}+\frac{d \lambda_{s}}{d t}-\frac{L_{s r d}}{\tau_{d s} \sigma_{s} L_{r}}\left[\frac{L_{r}}{L_{s r d}} \lambda_{s}-\frac{L_{r} L_{s d}}{L_{s r d}} i_{D s 1}^{s f}+L_{s r d} i_{D s 1}^{s f}\right]
$$




$$
v_{Q s 1}^{s f}=r_{q s} i_{Q s 1}^{s f}+L_{q s} \sigma_{s} \frac{d i_{Q s 1}^{s f}}{d t}+\frac{L_{s r d}}{L_{r}} \frac{d \lambda_{Q r}^{s f}}{d t}
$$

where,

$$
\sigma_{s}=1-L_{s r d}^{2} /\left(L_{r} L_{s d}\right)
$$

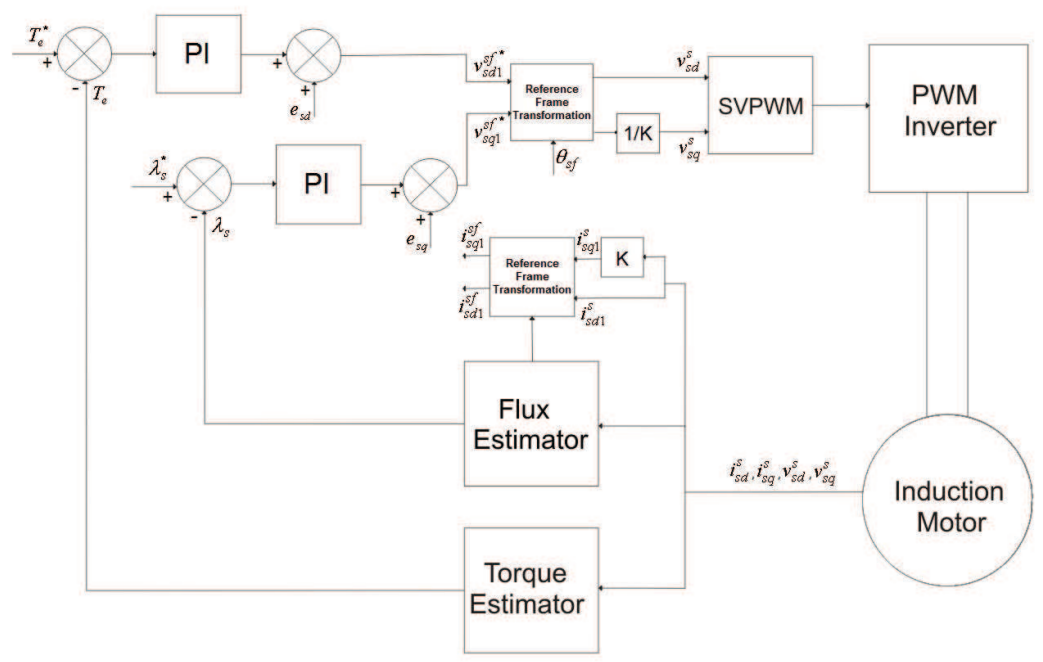

Fig. 7. SVPWM-DTC proposed scheme.

By manipulating (46) and (47) in the synchronous frame, the designed control signals can be obtained as:

$$
\begin{gathered}
v_{D s 1}^{s f}=\frac{\lambda_{s}}{\tau_{d s} \sigma_{s}}+\frac{d \lambda_{s}}{d t}+e_{d s} \\
v_{Q s 1}^{s f}=r_{q s} i_{Q s 1}^{s f}+L_{q s} \sigma_{s} \frac{d i_{Q s 1}^{s f}}{d t}+e_{q s}
\end{gathered}
$$

assuming the terms $e_{d s}$ and $e_{q s}$ as feed-forward elements and given by (51) and (52), and considering the terms that indicate the asymmetry and disturbance negligible:

$$
\begin{gathered}
e_{d s}=-\frac{L_{s r d}}{\tau_{d s} \sigma_{s} L_{r}}\left[\frac{L_{r}}{L_{s r d}} \lambda_{s}-\frac{L_{r} L_{d s}}{L_{s r d}} i_{s D 1}^{s f}+L_{s r d} i_{s D 1}^{s f}\right] \\
e_{q s}=\frac{L_{s r d}}{L_{r}}\left[\frac{r_{r} L_{s d}}{L_{s r d}} i_{s Q 1}^{s f}\right]
\end{gathered}
$$

The torque as function of stator flux and currents is given by: 


$$
T_{e}=p\left(i_{Q s 1}^{s f} \lambda_{D s 1}^{s f}-i_{D s 1}^{s f} \lambda_{Q s 1}^{s f}\right)
$$

A 4 poles, 1/4 HP, $110 \mathrm{~V}, 60 \mathrm{~Hz}$, asymmetrical 2-phase induction machine was used with the following parameters expressed in ohms (Krause et al., 1995):

$r_{d s}=2.02 ;$

$X_{l d}=2.79 ; X_{m d}=66.8$

$r_{q s}=7.14 ;$

$X_{l q}=3.22 ; X_{m q}=92.9$;

$r_{r}^{\prime}=4.12 ;$

$X_{l r}^{\prime}=2.12$.

The total inertia is $J=1.46 \times 10^{-2} \mathrm{kgm}^{2}$ and $N_{s d} / N_{s q}=1.18$, where $N_{s d}$ is the number of turns of the main winding and $N_{s q}$ is the number of turns of the auxiliary winding. It was considered a squirrel cage motor type with only the $d$ rotor axis parameters.

In terms of stator-flux field-orientation

$$
T_{e}=p\left(i_{Q s 1}^{s f} \lambda_{s}\right)
$$

According to (49) and (50), the stator flux control can be accomplished by $v_{D s 1}^{s f}$ and torque control by $v_{\mathrm{Qs}}^{s f}$. The stator voltage reference values $v_{D s 1}^{s f^{*}}$ and $v_{\mathrm{Q} s 1}^{s f *}$ are produced by two PI controllers. The stator flux position is used in a reference frame transformation to orient the $d q$ stator currents. Although there is a current loop to decouple the flux and torque control, the DTC scheme is seen as a control scheme operating with closed torque and flux loops without current controllers (Jabbar et al., 2004).

\section{Simulation results}

Some simulations were carried out in order to evaluate the control strategy performance. The motor is fed by an ideal voltage source. The reference flux signal is kept constant at 0.4 $\mathrm{Wb}$. The reference torque signal is given by: $(0,1,-1,0.5) \mathrm{Nm}$ at $(0,0.2,0.4,0.6) \mathrm{s}$, respectively. The SVPWM method used produced $d q$ axes voltages. The switching frequency was set to $5 \mathrm{kHz}$. Fig. 8 shows the actual value of the motor speed. In Fig. 9 and Fig. 10, the torque

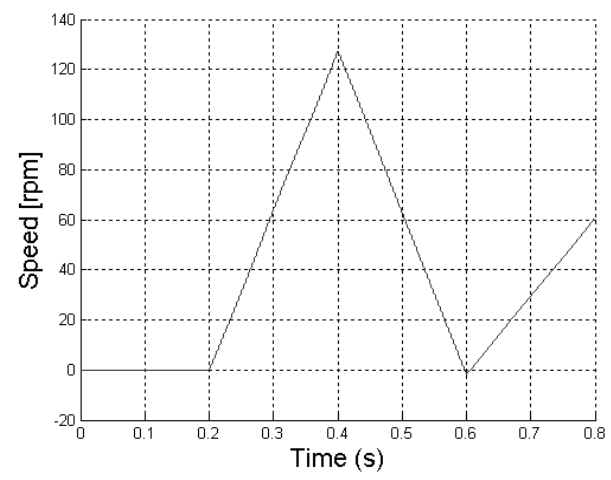

Fig. 8. Motor speed (rpm). 


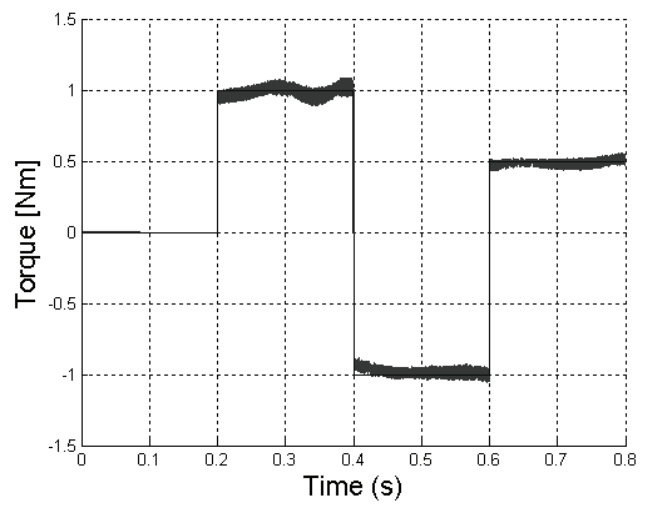

Fig. 9. Commanded and estimated torque (Nm).

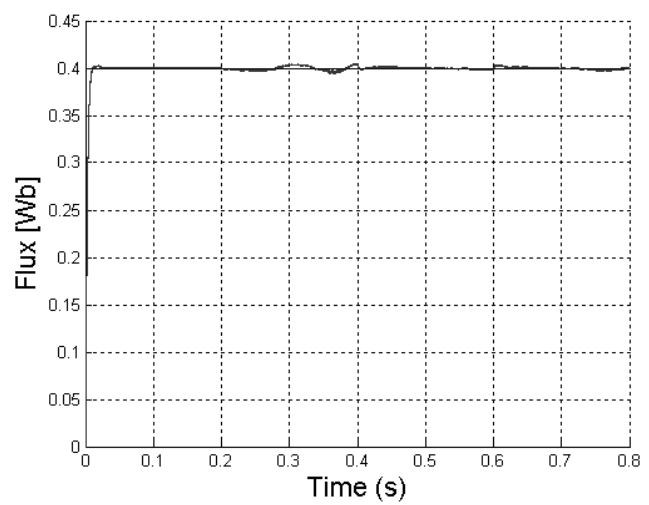

Fig. 10. Commanded and estimated flux

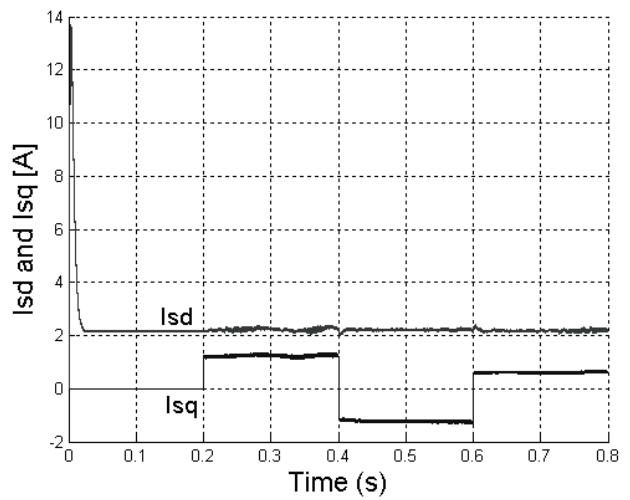

Fig. 11. Stator currents in stator flux reference frame. 
waveform and the flux waveform are presented. Although the torque presents some oscillations, the flux control is not affected. The good response in flux control can be seen. Fig. 11 shows the relation between the $d$ stator current component to the flux production and the $q$ stator current component to the torque production.

\section{Conclusion}

The investigation carried out in this paper showed that DTC strategy applied to a singlephase induction motor represents an alternative to the classic FOC control approach. Since the classic direct torque control consists of selection of consecutive states of the inverter in a direct manner, ripples in torque and flux appear as undesired disturbances. To minimize these disturbances, the proposed SVPWM-DTC scheme considerably improves the drive performance in terms of reduced torque and flux pulsations, especially at low-speed operation. The method is based on the DTC approach along with a space-vector modulation design to synthesize the necessary voltage vector.

Two PI controllers determine the $d q$ voltage components that are used to control flux and torque. Like a field orientation approach, the stators currents are decoupled but not controlled, keeping the essence of the DTC.

The transient waveforms show that torque control and flux control follow their commanded values. The proposed technique partially compensates the ripples that occur on torque in the classic DTC scheme. The proposed method results in a good performance without the requirement for speed feedback. This aspect decreases the final cost of the system. The results obtained by simulation show the feasibility of the proposed strategy.

\section{References}

Buja, G. S. and Kazmierkowski, M. P. (2004). Direct Torque Control of PWM Inverter-Fed AC Motors - A Survey, IEEE Transactions on Industrial Electronics, vol. 51, no. 4, pp. 744-757.

Campos, R. de F.; de Oliveira, J; Marques, L. C. de S.; Nied, A. and Seleme Jr., S. I. (2007a). SVPWM-DTC Strategy for Single-Phase Induction Motor Control, IEMDC2007, Antalya, Turkey, pp. 1120-1125.

Campos, R. de F.; Pinto, L. F. R.; de Oliveira, J.; Nied, A.; Marques, L. C. de S. and de Souza, A. H. (2007b). Single-Phase Induction Motor Control Based on DTC Strategies, ISIE2007, Vigo, Spain, pp. 1068-1073.

Corrêa, M. B. R.; Jacobina, C. B.; Lima, A. M. N. and da Silva, E. R. C. (2004).Vector Control Strategies for Single-Phase Induction Motor Drive Systems, IEEE Transactions on Industrial Electronics, vol. 51, no. 5, pp. 1073-1080.

Charumit, C. and Kinnares, V. (2009). Carrier-Based Unbalanced Phase Voltage Space Vector PWM Strategy for Asymmetrical Parameter Type Two-Phase Induction Motor Drives, Electric Power Systems Research, vol. 79, no. 7, pp. 1127-1135.

dos Santos, E.C.; Jacobina, C.B.; Correa, M. B. R. and Oliveira, A.C. (2010). Generalized Topologies of Multiple Single-Phase Motor Drives, IEEE Transactions on Energy Conversion, vol. 25, no. 1, pp. 90-99.

Jabbar, M. A.; Khambadkone, A. M. and Yanfeng, Z. (2004). Space-Vector Modulation in a Two-Phase Induction Motor Drive for Constant-Power Operation, IEEE Transactions on Industrial Electronics, vol. 51, no. 5, pp. 1081-1088. 
Jacobina, C. B.; Correa, M. B. R.; Lima, A. M. N. and da Silva, E. R. C. (1999). Single-phase Induction Motor Drives Systems, APEC'99, Dallas, Texas, vol. 1, pp. 403-409.

Krause, P. C.; O. Wasynczuk, O. and Sudhoff, S. D. (1995). Analysis of Electric Machinery. Piscataway, NJ: IEEE Press.

Neves, F. A. S.; Landin, R. P.; Filho, E. B. S.; Lins, Z. D.; Cruz, J. M. S. and Accioly, A. G. H. (2002). Single-Phase Induction Motor Drives with Direct Torque Control, IECON’02, vol.1, pp. 241-246.

Takahashi, I. and Noguchi, T. (1986). A New Quick-Response and High-Efficiency Control Strategy of an Induction Motor, IEEE Transactions on Industry Applications, vol. IA-22, no. 5, pp.820-827.

Noguchi, T. and Takahashi, I. (1997), High frequency switching operation of PWM inverter for direct torque control of induction motor, in Conf. Rec. IEEE-IAS Annual Meeting, pp. 775-780.

Wekhande, S. S.; Chaudhari, B. N.; Dhopte, S. V. and Sharma, R. K. (1999). A Low Cost Inverter Drive For 2-Phase Induction Motor, IEEE 1999 International Conference on Power Electronics and Drive Systems, PEDS'99, July 1999, Hong Kong.

$\mathrm{Hu}, \mathrm{J}$. and $\mathrm{Wu}, \mathrm{B}$. (1998). New Integration Algorithms for Estimating Motor Flux over a Wide Speed Range. IEEE Transactions on Power Electronics, vol. 13, no. 5, pp. 969977. 


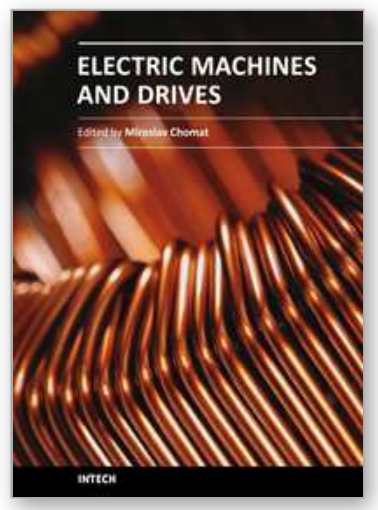

\author{
Electric Machines and Drives \\ Edited by Dr. Miroslav Chomat
}

ISBN 978-953-307-548-8

Hard cover, 262 pages

Publisher InTech

Published online 28, February, 2011

Published in print edition February, 2011

The subject of this book is an important and diverse field of electric machines and drives. The twelve chapters of the book written by renowned authors, both academics and practitioners, cover a large part of the field of electric machines and drives. Various types of electric machines, including three-phase and single-phase induction machines or doubly fed machines, are addressed. Most of the chapters focus on modern control methods of induction-machine drives, such as vector and direct torque control. Among others, the book addresses sensorless control techniques, modulation strategies, parameter identification, artificial intelligence, operation under harsh or failure conditions, and modelling of electric or magnetic quantities in electric machines. Several chapters give an insight into the problem of minimizing losses in electric machines and increasing the overall energy efficiency of electric drives.

\title{
How to reference
}

In order to correctly reference this scholarly work, feel free to copy and paste the following:

Ademir Nied, José de Oliveira, Rafael de Farias Campos, Seleme Isaac Seleme Jr. and Luiz Carlos de Souza Marques (2011). Space Vector PWM-DTC Strategy for Single-Phase Induction Motor Control, Electric Machines and Drives, Dr. Miroslav Chomat (Ed.), ISBN: 978-953-307-548-8, InTech, Available from: http://www.intechopen.com/books/electric-machines-and-drives/space-vector-pwm-dtc-strategy-for-singlephase-induction-motor-control

\section{INTECH}

open science | open minds

\section{InTech Europe}

University Campus STeP Ri

Slavka Krautzeka 83/A

51000 Rijeka, Croatia

Phone: +385 (51) 770447

Fax: +385 (51) 686166

www.intechopen.com

\section{InTech China}

Unit 405, Office Block, Hotel Equatorial Shanghai

No.65, Yan An Road (West), Shanghai, 200040, China

中国上海市延安西路65号上海国际贵都大饭店办公楼 405 单元

Phone: +86-21-62489820

Fax: $+86-21-62489821$ 
(C) 2011 The Author(s). Licensee IntechOpen. This chapter is distributed under the terms of the Creative Commons Attribution-NonCommercialShareAlike-3.0 License, which permits use, distribution and reproduction for non-commercial purposes, provided the original is properly cited and derivative works building on this content are distributed under the same license. 